\title{
A systematic mapping study about DevOps
}

\section{Un estudio de mapeo sistemático sobre DevOps}

\author{
Jonathan Guerrero $^{+1}(\mathbb{D})$, Karen Zúñiga ${ }^{(\mathbb{D})}$, Camilo Certuche ${ }^{(\mathbb{D})}$ and \\ César Pardo +2 (i) \\ + Grupo de Investigación GTI, Programa de Ingeniería de Sistemas, \\ Facultad de Ingeniería Electrónica y Telecomunicaciones, \\ Universidad del Cauca, Popayán, Colombia
}

\begin{abstract}
DevOps is a very trendy term these days in the software development companies (SDC), term that emerges as a possible solution to finally reach an acceleration and a rise of productivity expected with the appearance of agile development approaches, but that until now had not materialized, through automation practices, continuous integration, continuous build and continuous deployment. This paper aims to show current knowledge about the process of adopting DevOps in SDC through a systematic mapping of the literature. However, the results obtained show that there is little detailed information regarding activities, tasks, roles and other important process elements for the adoption of DevOps. Similarly, it has been concluded that there is no a unified terminology, therefore, it is important to standardize it to simplify the understanding and application of DevOps. Furthermore, this paper shows the preview of the framework that it is being developed for the adoption of DevOps in the SDC.
\end{abstract}

Keywords. Software development; software operations, DevOps, mapping systematic study.

Resumen. DevOps es un término muy de moda en estos días en las empresas de desarrollo de software (EDS), un término que surge como una posible solución para finalmente alcanzar una aceleración y un aumento en la productividad, que se esperaban con la aparición de los enfoques de desarrollo ágiles, pero que hasta ahora no se había materializado, a través de prácticas de automatización, integración continua, compilación continua y despliegue continuo. Este documento tiene como objetivo mostrar el conocimiento actual sobre el proceso de adopción de DevOps en EDS a través de un mapeo sistemático de la literatura. Sin embargo, los resultados obtenidos muestran que hay poca información detallada sobre actividades, tareas, roles y otros elementos de proceso importantes para la adopción de DevOps. Asimismo, se ha concluido que no hay una terminología unificada, por lo tanto, es importante homogeneizarla para facilitar la comprensión y la aplicación de DevOps. Adicionalmente, este documento muestra una vista previa del marco de trabajo que estamos desarrollando para la adopción de DevOps en EDS.

Palabras Claves. Desarrollo de software; operaciones de software, DevOps; estudio de mapeo sistemático.

How to Cite. J. Guerrero, K. Zuñiga, C. Certuche and C. Pardo, "A systematic mapping study about Devops", Jou. Cie. Ing., vol. 12, no. 1, pp. 48-62, 2020. doi:10.46571/JCI.2020.1.5

Received: 28/02/2020 Revised: 02/04/2020 Accepted: 07/08/2020

1 e-mail: jguerrero@unicauca.edu.co

2 e-mail: cpardo@unicauca.edu.co 


\section{Introduction}

The different software development trends have been evolving since their inception, always trying to achieve better practices that guarantee the delivery of high-quality products, meeting the industry standards and the real needs of customers. Within this evolution we find constantly emerging traditional frameworks such as: Rational Unified Process (RUP) [1], Capability Maturity Model Integration (CMMI) [2], Iconix [3], Microsoft Solutions Framework (MSF) [4], among others; Agile approaches such as: Scrum [5], Lean Software Development (LSD) [6], eXtreme Programming (XP) [7], Crystal Clear [8], Adaptive Software Development (ASD) [9], among others; and even hybrid solutions that integrate practices of both traditional and agile solutions (Scrumban [10], Scrum and XP [11], CMMI and Scrum [12], among others), from the homogenization of their differences, comparison and integration of best practices [13].

Agile approaches aim to constantly deliver products of excellence and deliver value to their customers, guaranteeing the rapid return on investment, and the option to being open to changes in customer needs over time and permanent environment changes [1]. Similarly, from the perspective of the operations area are de facto frameworks, such as: Information Technology Infrastructure Library (ITIL) [14] and Control Objectives for Information and Related Technologies (COBIT) [15], and international standards such as ISO/IEC20000 [16], where elements, practices and/or activities related to the administration of information technology (IT) services and the administration of continuous improvement processes in IT services are proposed.

Currently, Software Development Companies (hereinafter SDC) seek to further increase their productivity due to the high degree of competitiveness of the software industry [17], [18], which tends to integrate and institutionalize agile and less complex processes that allow it to adapt to business changes in a timely manner [19]. Despite the progress in the design of solutions, models or frameworks to support different processes in software development, these alone do not achieve the best results in highly productive environments that require to continuously deliver services to their customers, [20]. That is when DevOps appear, the combination of the words Development (Dev) and Operations (Ops). DevOps is a term that, despite existing ten years ago, is currently becoming stronger $[21,22]$. The main objective of DevOps is to unify the development and operation of the software in a single, integrated and continuous process, and try to break down the barriers between Dev and Ops [23]. From a DevOps approach, it is expected to take advantage of the experience and knowledge of people, processes and technology to stimulate collaboration and innovation throughout the software development and launch process [24], this done quickly, frequently and reliably [25], without sacrificing the quality and the value delivered to customers, distinctive characteristics of DNA in agile approaches but enhancing some of its benefits such as time to market [26].

In this regard, the objective of this systematic mapping focuses specifically on establishing a definition for DevOps, due to the different perceptions and definitions that can be found in the literature. Likewise, seeks to identify the solutions proposed by other authors about the conception of the implementation and / or operation of DevOps. After performing an analysis of the state of the art, some efforts are observed where solutions related to the adoption of DevOps in SDC have been proposed. Similarly, studies that identify aspects such as challenges and benefits that such adoption entails have been carried out. However, there are no studies with a sufficient level of detail to carry out the DevOps adopting process in a clear way and that describes a set of mechanisms that allow controlling what is related to DevOps [27]. In this regard, we consider that the systematic mapping carried out can be quite useful, since it synthesizes the current state of knowledge in DevOps, and it is also possible to establish the necessary attributes to develop a guide for the adoption, implementation and control of DevOps in the SDC. This paper is an extension of the conference paper presented in [28], unlike the paper presented previously, here we present in detail the categorization of the process elements 
(identified and presented in section 3.4), which, in this document, was carried out following a reference ontology, seeking to lessen the ambiguity in certain terms. Also, the analysis of the answer to question Q6 (section 3.6), where the tools mentioned in the primary studies are categorized according to the process or area to which they support, has been considerably extended. In addition, the main observations section (section 4.1) has been complemented, commenting on what was observed after analyzing the process elements found. Likewise, it is also presented a preview of what our proposed solution to the reported inconveniences that SDC face when carrying out the DevOps adoption.

This study is organized as follows: Section 2 describes the research protocol carried out to perform the systematic mapping. Section 3 contains the results obtained from such mapping. Section 4 discusses the main observations of the results, as well as the limitations and implications of this field. In addition, Section 5 presents the framework to support the effort related to DevOps that is being developed, and finally Section 6 presents the conclusions and future work to be done regarding the adoption of DevOps in SDC.

\section{Research protocol}

A systematic mapping is a method to collect and categorize existing information about a research topic. This systematic mapping was carried out following the guidelines presented in the following studies: [29-33]. The systematic mapping was carried out in three stages: Planning, Execution and Documentation.

\subsection{Planning Stage}

In the planning stage the following activities were carried out:

- Creation of research questions.

- Definition of the search strategy.

- Definition of the selection criteria for primary studies.

- Definition of the quality assessment criteria.

- Definition of the data extraction strategy.

- Assortment of the synthesis methods.

\subsection{Research questions}

In order to achieve the objective of systematic mapping and identify possible existing gaps to propose new areas of research, the research questions shown in Table 1 have been established.

Considering the related works, it is possible to observe that although there are different proposals that try to lessen some of the challenges of the SDC, there are no studies or proposals that consider the possible multi-model scenarios that can be generated in this type of environments.

\subsection{Search strategy}

For the search, combinations of the "AND" and "OR" logical connectors were used on the identified keywords. The databases: Scopus, Google Scholar, SpringerLink and IEEE Xplore were used, in which the adapted search string for each of the search engines was introduced. Similarly, studies provided by experts, which have been classified as grey literature were used. ("agile" OR "agile approach" OR "agile process") AND (DevOps OR "continuous delivery" OR "continuous release" OR "continuous deployment") AND (adopt OR integrate OR integration OR integrating) AND ("software development"). All information published from January 2009, date on which the term DevOps was first coined in the industry, [34] until June de 2020 was considered. This period of time has been validated during the execution of the systematic 


\begin{tabular}{|l|l|}
\hline \hline Research questions & Motivation \\
\hline \hline $\begin{array}{l}\text { Q1. According to the analyzed literature, } \\
\text { what is understood by DevOps? }\end{array}$ & $\begin{array}{l}\text { An approach to a standard DevOps definition is } \\
\text { sought in the software environment. }\end{array}$ \\
\hline $\begin{array}{l}\text { Q2. What kind of instruments or } \\
\text { research methods are used in the analyzed } \\
\text { literature? }\end{array}$ & $\begin{array}{l}\text { To determine research instruments or methods } \\
\text { most commonly used in solving research ques- } \\
\text { tions regarding DevOps. }\end{array}$ \\
\hline $\begin{array}{l}\text { Q3. What kind of solutions have been } \\
\text { proposed to simplify the adoption of } \\
\text { DevOps in the SDC? }\end{array}$ & $\begin{array}{l}\text { To determine the state of the art related to the } \\
\text { adoption of DevOps, and establish the work to } \\
\text { be done or to be improved. }\end{array}$ \\
\hline $\begin{array}{l}\text { Q4. What are the process elements that } \\
\text { have been considered to apply DevOps? }\end{array}$ & $\begin{array}{l}\text { To examine documented proposals, their ap- } \\
\text { proach, completeness and applicability. }\end{array}$ \\
\hline $\begin{array}{l}\text { Q5. What types of software development } \\
\text { projects is DevOps used for? }\end{array}$ & $\begin{array}{l}\text { To determine the types of software project } \\
\text { development: standalone, web or mobile, on } \\
\text { which the adoption of DevOps has been carried } \\
\text { out. }\end{array}$ \\
\hline $\begin{array}{l}\text { Q6. What technological tools are used to } \\
\text { simplify the adoption of DevOps? }\end{array}$ & $\begin{array}{l}\text { To know the technological tools that support } \\
\text { some type of activity to simplify the adoption } \\
\text { of DevOps. }\end{array}$ \\
\hline $\begin{array}{l}\text { Q7. What benefits and challenges does the } \\
\text { adoption of DevOps entail? }\end{array}$ & $\begin{array}{l}\text { To determine the benefits and challenges } \\
\text { companies that carry out the adoption of } \\
\text { DevOps face. }\end{array}$ \\
\hline
\end{tabular}

Table 1: Research questions

mapping, and most of the relevant publications about the adoption of DevOps are from 2009, especially in the last six years $(2014-2020)$.

\subsection{Selection criteria}

The collected studies were evaluated considering the title, abstract and keywords, to determine whether or not they were included among the relevant studies. Then, they were analyzed in detail to select the primary studies. Those studies that met at least one of the following inclusion criteria were included: i) Studies in English that refer to the adoption of DevOps in software development companies and ii) Studies published between 2009 and 2020 in journals, conferences, prestigious congresses or workshops with peer review. On the other hand, studies that met any of the following exclusion criteria were not taken into account: i) Duplicate studies, ii) Studies whose main contribution is not related to the adoption of DevOps in SDC, iii) studies that contemplate the topic superficially iv) Types of debate studies, or available only in the form of abstracts or presentations.

\subsection{Quality Evaluation Criteria}

To measure the quality of the selected studies and to determine the relevant studies about the adoption of DevOps in SDC, a questionnaire with a scoring system of three values was developed $(-1,0$ and +1$)$. The quality criteria established to evaluate the primary studies are explained in [28]. Table 2 presents the results of the evaluation of the studies according to the quality evaluation criteria. The sum of the score of each study will correspond to the final score (obtaining a value between -6 and +6 ). These scores will not be used to exclude a specific study from the systematic mapping, instead, in the event of obtaining a poor score, it will be used to find more relevant studies, which will have more relevance in future researches. 


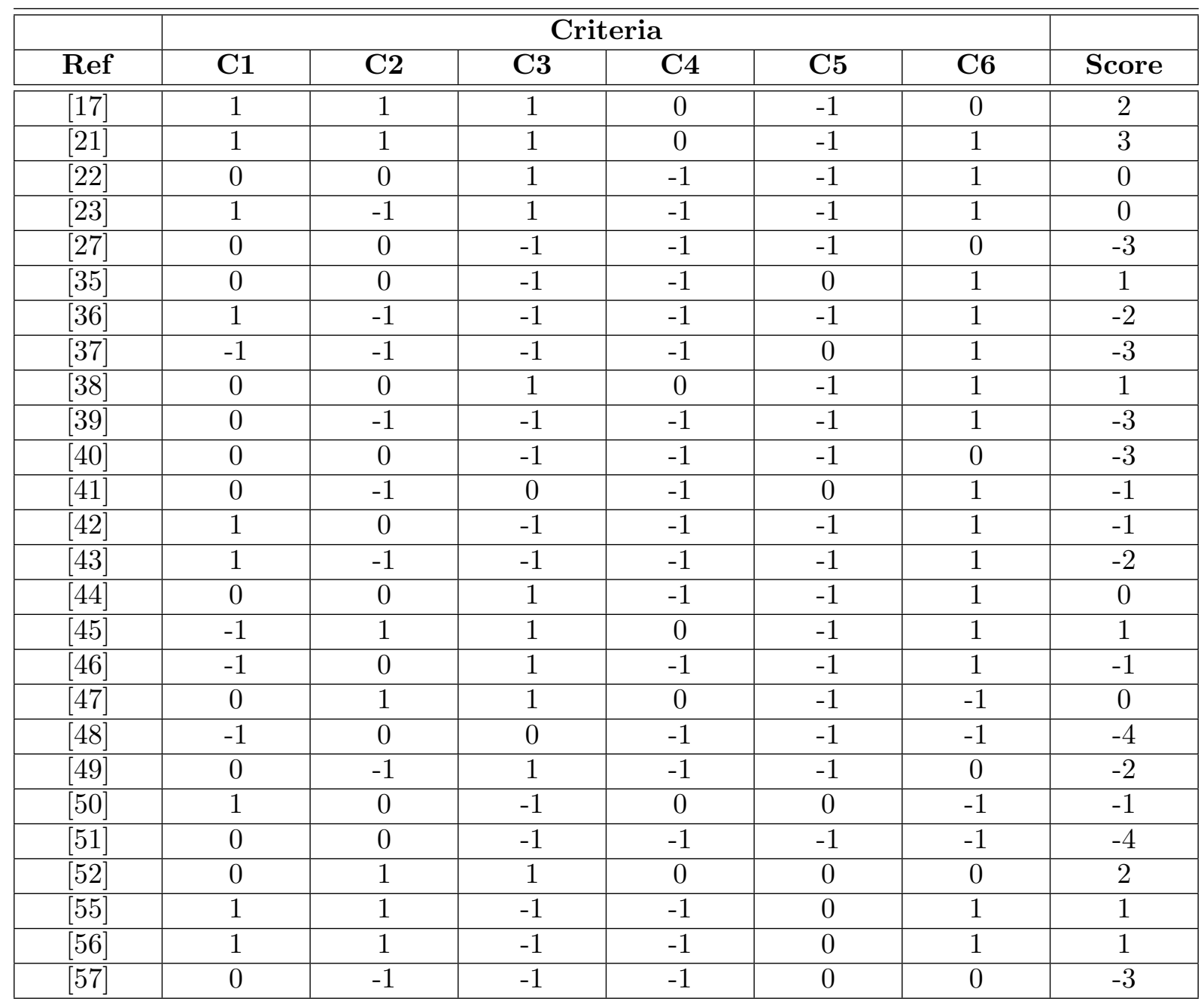

Table 2: Evaluation of the studies according to the quality evaluation criteria.

\subsection{Data Extraction Strategy}

To ensure the application of the same data extraction criteria for all the selected studies and simplify their classification, a set of possible answers was used for each of the defined research questions, as shown in Table 3.

\subsection{Synthesis method}

The information of the selected primary studies was extracted and structured as follows: identification (title, publication, authors, reference), abstract, description (methodology, type of proposal, type of evaluation of the proposal) and highlighted aspects. Table 4 shows the relationship of the primary studies to the research questions that each one answered.

\subsection{Execution Stage}

Five iterations were carried out, a zero iteration where an initial review of grey literature was carried out which consisted of 10 articles, this review allowed us to know more in-depth the concepts which DevOps is usually associated with, in order to refine the final search string, then a new iteration was performed for each established search source. Table 5 shows the total number of studies: found, relevant, repeated and primary, acquired in the search sources of 


\begin{tabular}{|l|l|}
\hline \hline Questions & Answers \\
\hline \hline $\begin{array}{l}\text { Q1. According to the analyzed literature, } \\
\text { what is understood by DevOps? }\end{array}$ & $\begin{array}{l}\text { a. Gap between development and operations, } \\
\text { b. Culture of collaboration and communication, } \\
\text { c. Integration, delivery and continuous deploy- } \\
\text { ment, d. Quality assurance, e. Automation, f. } \\
\text { Others }\end{array}$ \\
\hline $\begin{array}{l}\text { Q2. What kind of instruments or } \\
\text { research methods are used in the analyzed } \\
\text { literature? }\end{array}$ & $\begin{array}{l}\text { a. Systematic mapping / Literature review, b. } \\
\text { Case study, c. Survey / interview, d. Proposals, } \\
\text { e. Others }\end{array}$ \\
\hline $\begin{array}{l}\text { Q3. What kind of solutions have been } \\
\text { proposed to simplify the adoption of } \\
\text { DevOps in the SDC? }\end{array}$ & $\begin{array}{l}\text { a. Approaches, b. Model, c. Methodology, d. } \\
\text { Technique, e. Framework, f. Others, g. No } \\
\text { concrete solution is proposed }\end{array}$ \\
\hline $\begin{array}{l}\text { Q4. What are the process elements that } \\
\text { have been considered to apply DevOps? }\end{array}$ & $\begin{array}{l}\text { a. Roles, b. Practices, c. Activities, d. } \\
\text { Templates, e. Artifacts, f. Others }\end{array}$ \\
\hline $\begin{array}{l}\text { Q5. What types of software development } \\
\text { projects is DevOps used for? }\end{array}$ & $\begin{array}{l}\text { a. Standalone, b. Web, c. Mobile, d. The type } \\
\text { of project is not clarified }\end{array}$ \\
\hline $\begin{array}{l}\text { Q6. What technological tools are used to } \\
\text { simplify the adoption of DevOps? }\end{array}$ & $\begin{array}{l}\text { a. Tools for integration, delivery and continuous } \\
\text { deployment, b. Tools to promote communica- } \\
\text { tion and collaboration, c. Others }\end{array}$ \\
\hline $\begin{array}{l}\text { Q7. What benefits and challenges does the } \\
\text { adoption of DevOps entail? }\end{array}$ & $\begin{array}{l}\text { a. Economic, b. Improves processes, c. } \\
\text { Improves collaboration and communication, d. } \\
\text { Quality assurance, e. Customer satisfaction, } \\
\text { f. Productivity improvement, g. Resistance to } \\
\text { change, h. Others }\end{array}$ \\
\hline
\end{tabular}

Table 3: Classification scheme.

Scopus, Google Scholar, Springer e IEEE Xplore.

\section{Results}

Below are the results obtained for each of the research questions defined in the creation of this systematic mapping which are duly referenced to enable further in-depth study by the reader.

\subsection{Question Q1: According to the analyzed literature, what is understood by DevOps?}

Different definitions for DevOps were found in the analyzed literature, it seems that a definition or a common understanding of what DevOps implies has not yet been reached [43], so some definitions may be characterizing DevOps from a very specific perspective [43]. When analyzing each definition, the common characteristics and / or aspects (hereinafter concepts) that the authors have considered to define DevOps were identified. The common concepts that have been identified in the definitions are: (i) Collaboration and Communication, (ii) Development and Operations, (iii) Cover the gap, (iv) Quality Assurance, (v) Automation, (vi) Integration, delivery and continuous deployment and (vii) Set of practices.

According to the analyzed studies, it was also observed that DevOps represents: an approach $[35,52,55]$, a cultural movement $[17,57]$, a set of practices $[23,27]$, an emerging paradigm $[38,56]$, a mixture of two words [39], a phenomenon [40], an interdisciplinary theme [22], a set of principles [41], a conceptual framework [42], a development methodology [51], an artificial word [44], a philosophy [47] and a neologism [36]. From the above, it can be evidenced that DevOps has been interpreted in several ways because it is a relatively new subject. 


\begin{tabular}{|c|c|c|c|c|c|c|c|}
\hline \hline \multicolumn{7}{|c|}{ Question } \\
\hline Ref & Q1 & Q2 & Q3 & Q4 & Q5 & Q6 & Q7 \\
\hline \hline$[17]$ & $\mathrm{X}$ & $\mathrm{X}$ & $\mathrm{X}$ & & & & \\
\hline$[21]$ & $\mathrm{X}$ & $\mathrm{X}$ & $\mathrm{X}$ & $\mathrm{X}$ & & $\mathrm{X}$ & $\mathrm{X}$ \\
\hline$[22]$ & $\mathrm{X}$ & & $\mathrm{X}$ & $\mathrm{X}$ & & $\mathrm{X}$ & $\mathrm{X}$ \\
\hline$[23]$ & $\mathrm{X}$ & $\mathrm{X}$ & $\mathrm{X}$ & & & & $\mathrm{X}$ \\
\hline$[27]$ & $\mathrm{X}$ & $\mathrm{X}$ & $\mathrm{X}$ & $\mathrm{X}$ & $\mathrm{X}$ & $\mathrm{X}$ & $\mathrm{X}$ \\
\hline$[35]$ & $\mathrm{X}$ & $\mathrm{X}$ & $\mathrm{X}$ & $\mathrm{X}$ & & & $\mathrm{X}$ \\
\hline$[36]$ & $\mathrm{X}$ & $\mathrm{X}$ & $\mathrm{X}$ & & & & $\mathrm{X}$ \\
\hline$[37]$ & & $\mathrm{X}$ & $\mathrm{X}$ & & & & $\mathrm{X}$ \\
\hline$[38]$ & $\mathrm{X}$ & & $\mathrm{X}$ & & & & \\
\hline$[39]$ & $\mathrm{X}$ & & $\mathrm{X}$ & & & & $\mathrm{X}$ \\
\hline$[40]$ & $\mathrm{X}$ & $\mathrm{X}$ & $\mathrm{X}$ & $\mathrm{X}$ & & & $\mathrm{X}$ \\
\hline$[41]$ & $\mathrm{X}$ & & $\mathrm{X}$ & & & & \\
\hline$[42]$ & $\mathrm{X}$ & $\mathrm{X}$ & $\mathrm{X}$ & $\mathrm{X}$ & & $\mathrm{X}$ & $\mathrm{X}$ \\
\hline$[43]$ & $\mathrm{X}$ & $\mathrm{X}$ & $\mathrm{X}$ & & $\mathrm{X}$ & & \\
\hline$[44]$ & $\mathrm{X}$ & $\mathrm{X}$ & $\mathrm{X}$ & $\mathrm{X}$ & $\mathrm{X}$ & $\mathrm{X}$ & \\
\hline$[45]$ & & $\mathrm{X}$ & $\mathrm{X}$ & $\mathrm{X}$ & $\mathrm{X}$ & $\mathrm{X}$ & \\
\hline$[46]$ & & $\mathrm{X}$ & $\mathrm{X}$ & $\mathrm{X}$ & $\mathrm{X}$ & $\mathrm{X}$ & \\
\hline$[47]$ & $\mathrm{X}$ & $\mathrm{X}$ & $\mathrm{X}$ & $\mathrm{X}$ & & $\mathrm{X}$ & \\
\hline$[48]$ & & $\mathrm{X}$ & $\mathrm{X}$ & & & & \\
\hline$[49]$ & $\mathrm{X}$ & $\mathrm{X}$ & $\mathrm{X}$ & & & & $\mathrm{X}$ \\
\hline$[50]$ & $\mathrm{X}$ & $\mathrm{X}$ & $\mathrm{X}$ & $\mathrm{X}$ & $\mathrm{X}$ & $\mathrm{X}$ & $\mathrm{X}$ \\
\hline$[51]$ & $\mathrm{X}$ & $\mathrm{X}$ & $\mathrm{X}$ & $\mathrm{X}$ & & $\mathrm{X}$ & \\
\hline$[52]$ & $\mathrm{X}$ & $\mathrm{X}$ & $\mathrm{X}$ & $\mathrm{X}$ & & $\mathrm{X}$ & \\
\hline$[55]$ & $\mathrm{X}$ & $\mathrm{X}$ & $\mathrm{X}$ & $\mathrm{X}$ & $\mathrm{X}$ & & \\
\hline$[56]$ & $\mathrm{X}$ & $\mathrm{X}$ & $\mathrm{X}$ & $\mathrm{X}$ & & $\mathrm{X}$ & \\
\hline$[57]$ & $\mathrm{X}$ & $\mathrm{X}$ & $\mathrm{X}$ & & & & \\
\hline & & & \multicolumn{2}{|c|}{} & & & \\
\hline
\end{tabular}

Table 4: Contributions of the primary studies to each research question.

\begin{tabular}{|l|l|l|l|l|l|}
\hline \hline No. & Data source & Found & Relevant & $\begin{array}{l}\text { Relevant repeated } \\
\text { (Previous iterations) }\end{array}$ & $\begin{array}{l}\text { Primary } \\
\text { selected }\end{array}$ \\
\hline \hline 0 & Grey Literature & 10 & 9 & 0 & 7 \\
\hline 1 & Scopus & 522 & 10 & 7 & 3 \\
\hline 2 & Google Scholar & 219 & 7 & 4 & 6 \\
\hline 3 & Springer & 487 & 8 & 4 & 4 \\
\hline 4 & IEEE Xplore & 42 & 3 & 3 & 3 \\
\hline & Total & 1280 & 37 & 18 & $\mathbf{2 3}$ \\
\hline
\end{tabular}

Table 5: Classification scheme 


\subsection{Question Q2: What type of research is carried out in the analyzed literature?}

The studies selected in this research can be divided into two categories: (i) studies with concrete proposals on the adoption of DevOps $[17,23,40,44-47,49,50,56]$ and (ii) systematic reviews of literature $[21,27,35,36,42,48,55,57]$. Regarding the first category, it was found that $90 \%$ of the studies $[17,23,40,44-47,49,50]$ registered on the adoption of DevOps use case studies to validate their proposals, these Case studies have been carried out in a range of one to five years in their application depending on the size of the project. On the other hand, from these studies $77 \%[17,23,40,44-46,49]$ complement the findings with surveys and / or interviews to determine the impact at the level of culture and organization. Regarding the second category, only $38 \%[21,36,48]$ of them use their findings to propose, even if in a conceptual way, some solution for the implementation of DevOps with some agile framework.

\subsection{Question Q3: What kind of solutions have been proposed for the adoption of DevOps?}

$20 \%[17,21,38,45,56]$ of the analyzed literature propose concrete solutions to guide the SDC in the adoption of DevOps. On the other hand, $80 \%$ [22, 23, 27, 35-37, 39-44, 46-52, 55, 57] of the analyzed studies, do not propose a concrete solution for the adoption of DevOps in SDC, but rather describe their experience in adopting DevOps. It is possible to observe that $56 \%[17,21,22,27,35-37,39-42,49,50,56]$ identify benefits and challenges, in addition, $60 \%[17,21-23,35,40,41,44,46-48,51,52,55,56]$ propose a set of process elements that could be considered for the adoption of DevOps. Similarly, 40\%. [21,27,42,44-47,50,52,56] mention the technological tools that could support practices to adopt DevOps. It is important to mention that detailed information on the benefits and challenges that were identified in the analyzed literature is available in [28].

\subsection{Question Q4: What are the process elements that have been considered to apply DevOps?} After analyzing the primary studies, it was possible to observe that $60 \%$ (15 studies out of 25 in total) of them propose or mention process elements, which were categorized according to the process elements proposed in the Ontology of Process-reference Models - PrMO [53]. PrMO defines concepts and their own definitions and relationships for process elements such as: process, activity, work products, role and tool. The ontology also defines other concepts for process elements such as process category and tasks, however, since no such process elements were found, they are not mentioned in this work. Due to space limitations in Table 6 only some process elements identified in each of the selected studies are presented, in this sense, the column Activity and Tool just show the amount of activities and tools, respectively, the complete table with all activities identified is found in: https://bit.ly/2VCTdyK. As regards to the tools, these are listed in the Table 7 . From the total of selected primary studies, it was identified that $46 \%$ of them propose processes that support DevOps, from the processes that support studies are those related to: continuous integration, continuous delivery, continuous supervision, continuous deployment, quality assurance, configuration process, DevOps Framework Approach. Likewise, $38 \%$ of the studies propose activities, $8 \%$ work products, $38 \%$ roles, $69 \%$ technological tools and $31 \%$ propose other process elements, for example: areas or dimensions. It should be considered that a study can propose several process elements and that these can support different processes. Table 6 shows only the number of tools proposed by each author because the technological tools that support DevOps are addressed in depth in the research question Q6.

\subsection{Question Q5: What types of software development projects (standalone, web or mobile) is DevOps used for?}

$100 \%$ of the selected studies describing software development projects with evidence of progress or proposals in the adoption of DevOps make use of Cloud services, for example: continuous integration services, monitoring, among others $[17,23,40,44-47,49,50]$ and there are no studies 


\begin{tabular}{|c|c|c|c|c|c|}
\hline & \multicolumn{5}{|c|}{ Process Element } \\
\hline Ref & Process & Activity & Product & Rol & Tool \\
\hline$[21]$ & NF & NF & $\begin{array}{l}\text { List of impediments, } \\
\text { DevOps maturity } \\
\text { model, DevOps tool } \\
\text { list, DevOps tool list } \\
\text { used in the company }\end{array}$ & NF & 45 \\
\hline$[22]$ & $\mathrm{NF}$ & $\mathrm{NF}$ & $\mathrm{NF}$ & $\begin{array}{lr}\text { Software } & \text { Development } \\
\text { Manager, } & \text { Developer } \\
\text { and Test } & \text { Analyst with } \\
\text { DevOps approach, } \\
\text { Systems Manager }\end{array}$ & 4 \\
\hline$[27]$ & $\mathrm{CD}, \mathrm{DC}, \mathrm{QA}$ & 11 activities & $\mathrm{NF}$ & NF & 19 \\
\hline$[35]$ & $\mathrm{NF}$ & $\mathrm{NF}$ & $\mathrm{NF}$ & $\begin{array}{lr}\text { Engineer, } & \text { Team and } \\
\text { DevOps Department, } & \text { Dent } \\
\text { Developer with DevOps } \\
\text { approach, } \\
\text { Manager }\end{array}$ & $\mathrm{NF}$ \\
\hline$[40]$ & $\mathrm{NF}$ & 24 activities & $\mathrm{NF}$ & NF & $\mathrm{NF}$ \\
\hline$[42]$ & $\begin{array}{l}\text { Measurement, } \\
\text { Automation }\end{array}$ & 19 activities & $\mathrm{NF}$ & $\mathrm{NF}$ & 2 \\
\hline$[44]$ & $\mathrm{DC}$ & 2 activities & $\mathrm{NF}$ & $\mathrm{NF}$ & 2 \\
\hline$[45]$ & $\mathrm{NF}$ & $\mathrm{NF}$ & $\mathrm{NF}$ & $\begin{array}{l}\text { Developer with DevOps } \\
\text { approach, Product } \\
\text { owner, Project Leader, } \\
\text { Team leader, Program } \\
\text { Manager, } \\
\text { Manager }\end{array}$ & 1 \\
\hline$[46]$ & CI, CD, CS & $\mathrm{NF}$ & $\mathrm{NF}$ & DevOps Team & 1 \\
\hline$[47]$ & PC, DFA & 10 activities & $\mathrm{NF}$ & $\mathrm{NF}$ & 4 \\
\hline$[50]$ & $\mathrm{NF}$ & $\mathrm{NF}$ & $\mathrm{NF}$ & $\mathrm{NF}$ & 14 \\
\hline$[51]$ & CI, CD, DC & 3 activities & $\mathrm{NF}$ & $\mathrm{NF}$ & 5 \\
\hline$[52]$ & $\mathrm{NF}$ & $\mathrm{NF}$ & $\mathrm{NF}$ & $\begin{array}{l}\text { Product Owner, Archi- } \\
\text { tect, Production Engi- } \\
\text { neer, Launch Manager }\end{array}$ & $\mathrm{NF}$ \\
\hline$[56]$ & CI, CS, DC & $\mathrm{NF}$ & NF & $\mathrm{NF}$ & 29 \\
\hline Ref: & $\begin{array}{r}\text { eference; NF: } \\
\text { CS: continu } \\
\text { PC }\end{array}$ & $\begin{array}{l}\text { ormation no } \\
\text { supervision } \\
\text { onfiguration }\end{array}$ & $\begin{array}{l}\text { ound; CI: continuous int } \\
\text { C: continuous deployme } \\
\text { ocess; DFA: DevOps Fra }\end{array}$ & $\begin{array}{l}\text { ration; CD: continuous d } \\
\text { t; QA: quality assurance; } \\
\text { ework Approach }\end{array}$ & livery \\
\hline
\end{tabular}

Table 6: Process elements related to DevOps identified by study. 


\begin{tabular}{|c|c|c|c|}
\hline No. & Area/Process & $\%$ & Tool \\
\hline 1 & $\begin{array}{l}\text { Source control man- } \\
\text { agement (Reposi- } \\
\text { tory) }\end{array}$ & $\overline{12}$ & $\begin{array}{l}\text { Github }[21,27,47,50] \text {, Bitbucket }[21,22,27] \text {, GitLab }[21 \text {, } \\
56] \text {, Mercurial }[22], \text { Apache Subversion }[21,56] \text {, SonarQube } \\
{[50,56] \text {, Maven }[47,56]}\end{array}$ \\
\hline 2 & $\begin{array}{l}\text { Continuous integra- } \\
\text { tion and orchestra- } \\
\text { tion }\end{array}$ & 13 & $\begin{array}{l}\text { Codeship }[21,27] \text {, Travis CI }[21,27,56] \text {, Jenkins }[21,22 \text {, } \\
27,44,47,50,56] \text {, Atlassian bamboo [21], Circle CI }[21] \text {, } \\
\text { TeamCity [21], Rancher [51], Gitflow [45] }\end{array}$ \\
\hline 3 & IaaS/PaaS & 2 & Heroku $[27,56]$ \\
\hline 4 & $\begin{array}{l}\text { Infrastructure as } \\
\text { code }\end{array}$ & 2 & Amazon cloudformation $[50,56]$ \\
\hline 5 & Monitoring & 20 & $\begin{array}{l}\text { Nagios }[21,27,42,56] \text {, New Relic }[27,50] \text {, AWS CloudWatch } \\
{[21,27] \text {, Apache Kafka [46], Zabbix [21,56], Splunk [21,51], }} \\
\text { AppDynamics [21], Bugzilla [21], Track \& TesTtrack [21], } \\
\text { MantisBT [21], Assembla [21], Kinesis [21] }\end{array}$ \\
\hline 6 & $\begin{array}{lr}\text { Managing } & \text { and } \\
\text { database } & \text { manage- } \\
\text { ment } & \end{array}$ & 7 & $\begin{array}{l}\text { MongoDB [27], DBMaestro [21], LiquiBase [21], RedGate } \\
{[21]}\end{array}$ \\
\hline 7 & Record / Security & 3 & Loggly [27], Papertrail [27] \\
\hline 8 & Testing & 8 & $\begin{array}{l}\text { Cucumber }[21,27] \text {, Junit }[27,56] \text {, Selenium }[21,50] \text {, } \\
\text { TestComplete [21], Jmeter }[21]\end{array}$ \\
\hline 9 & Collaboration & 5 & Slack $[21,27]$, HipChat $[21,22,27]$, PagerDuty $[21]$ \\
\hline 10 & Containerization & 8 & $\begin{array}{l}\text { Docker [21, 25, 47, 50], Mercurial [21], Bitbucket [50], } \\
\text { Rocker [21], Vagrant [21] }\end{array}$ \\
\hline 11 & $\begin{array}{l}\text { Configuration Man- } \\
\text { agement }\end{array}$ & 10 & $\begin{array}{l}\text { Docker }[21,47,50,56], \text { Puppet }[21,27,42,50,51] \text {, Ansible } \\
{[21,27,50], \text { Cheff }[21,50,51,56], \text { Vagrant }[21], \text { SaltStack }[21]}\end{array}$ \\
\hline 12 & Knowledge exchange & 5 & Crowdbase [21], Nuclion [21], Confluence [21], Trello [56] \\
\hline 13 & Planning & 5 & Clarizen [21], Confluence [21], Asana [21] \\
\hline \multicolumn{2}{|r|}{ Total } & 100 & 60 tools \\
\hline
\end{tabular}

Table 7: Technological tools that support DevOps processes / areas.

where the creation of services to support practices related to the adoption of DevOps over local networks is proposed. Only in [46] describes artifacts and specific practices for the adoption of DevOps in mobile development environments, the other proposals are focused on Web environments

3.6. Question Q6: What technological tools are used to simplify the adoption of DevOps? A total of 60 technological tools that support the processes involved in the adoption of DevOps were identified; to classify them, the catalog defined in [27]. Table 7 shows the areas or processes in which the tools were categorized, the percentage of tools found in each area, the names of the tools along with their reference. It was observed that the most used tools in the industry are: (i) Github, (ii) Jenkins, (iii) Puppet and (iv) Docker.

\subsection{Question Q7: What benefits and challenges does the adoption of DevOps entail?}

In the analyzed literature it is observed that the adoption of DevOps in the SDC entails certain benefits, including: (i) response time (time to market) that a product takes from the moment it is conceived until it is for sale: $[22,23,27,36,37,49]$, (ii) to close the gap between Dev and Ops: $[22,23,27,36,49]$, (iii) improved product quality: $[22,37,42,50]$ and (iv) improved customer 
satisfaction: $[36,37,49]$. In addition to the benefits that the DevOps adoption entails, certain challenges that hinder this adoption process were identified, these include: (i) resistance to change from the people: $[21-23,27,40,49]$, (ii) lack of understanding of the meaning of DevOps: $[21,23,39,40]$, (iii) lack of collaboration between development and operations: $[21,23,35,39]$ and (iv) to change the culture of the company: $[21-23,40]$. The detailed list of benefits and challenges that were identified in the analyzed literature is found in [28].

\section{Discussion}

This section presents an analysis of the results obtained from the systematic mapping performed, in order to identify the improvements that can be made on the proposals found.

\subsection{Main observations}

The objective of this systematic mapping is to know the current status of the adoption of DevOps in SDC. In this regard, after analyzing the results, it can be deduced that according to the analysis of what DevOps represents in the analyzed studies, "neologism" is the term that would characterize and classify most of the definitions. In addition, it is observed that this neologism refers to the cultural movement to which a company must adapt to adopt DevOps. Also, it is clear that DevOps is not only a set of practices, but it is related to all suggestion at the level of tasks, activities, artifacts, templates and roles. Therefore, it is considered more appropriate to use the term "process elements". Since there are definitions that do not take into account some of the common concepts identified, the following definition of DevOps is proposed: DevOps is a neologism that arises from the combination of the words Development and Operations. It is a cultural movement that allows to bridge the gap between developers and operations personnel. DevOps is related to a set of process elements that foster collaboration and communication, automation, quality assurance and integration, delivery and continuous deployment.

A large part of the proposals for the adoption of DevOps is focused on the practices of continuous integration, continuous deployment and process automation. However, the defined proposals are not very elucidated, so there is still a long way to go in the definition of standards for the contextualized appropriation of this cultural movement that impacts software projects from different perspectives such as architecture, culture, people, processes and tools.

As for process elements to support DevOps, it has been observed that these are not clearly defined, some of them are only identified, but not thoroughly described, even, the definitions of the process elements are ambiguous, and in most cases, incomplete. The authors propose activities and / or tasks that involve the adoption of DevOps, but do not explain carefully how to implement them nor what roles are responsible for executing them. As for the roles, it is only mentioned that it is necessary to have advanced knowledge about DevOps, however, they do not deepen in their assigned responsibilities, the stage in which they participate, among others. It was also possible to observe that the authors define the process elements according to their experience and not to a standard or model. In addition, it was not evidenced in the analyzed studies a detailed analysis of the specific activities that should be performed in each process supported by DevOps. Neither in the conducted case studies, was seen proof of a notable improvement in the productivity achieved by applying DevOps in the case studies companies.

\subsection{Limitations of the systematic mapping}

The limitation to academic search engines represents the state of the art of the research on the adoption of DevOps in SDC. The inclusion of studies only in English may mean that relevant studies in other languages are not considered, nonetheless English is the language most used to publish studies on this subject. In addition, although this systematic mapping has yielded relevant results, they serve as a starting point for a later version of the systematic mapping presented here. 


\subsection{Importance for research and practice}

The observations of this systematic mapping are of great importance to those researchers who are planning to research DevOps, and more specifically in the issue of the adoption of DevOps in SDC. For researchers it is an area of great interest, since, as it has been noted, it is a new field, in which there is little work done. Researchers, thanks to the development in this field, will be able to create guides that allow the adoption, implementation and control of DevOps correctly, or improve the existing practices that companies are currently adopting to implement DevOps, so that good practices of DevOps in SDC can be consolidated. Finally, organizations will be greatly benefited by the progress of this field, because so far, some organizations have developed and implemented DevOps according to their own criteria which they have considered appropriate, however, this has been carried out without a detailed evaluation of the results achieved in terms of the benefits obtained.

\section{A Framework to support the effort related to DevOps}

In order to address the main issues identified in this systematic mapping, a framework to support the effort related to DevOps is being developed, Figure 1 shows the structure of the framework which is composed of the following elements:

- DevOps Ontology allows understanding and organizing the knowledge related to the terms and relationships involved in the DevOps adoption process. This ontology uses as a basis the PrMO (Ontology of Process-reference Models) [53] and SMO (Software Measurement Ontology) [54].

- The reference model (DevOps Model) defines a set of fundamental process elements to consider (activities, roles, products, tools) for the adoption of DevOps. These elements will be categorized by the dimensions: (i) processes, (ii) technology, (iii) people and (iv) culture

- DevOps Process: software development process that includes the analysis, design and implementation phases, through the incorporation of the best practices of Agile and DevOps approaches, to enhance the development, integration and continuous deployment.

- DevOps Evaluation Model: solution that allows the evaluation of the adoption of DevOps from the reference model DevOps Model and DevOps Process.

- Tools: includes a set of electronic guides that simplifies the understanding of the DevOps reference model and the DevOps adoption process with agile methodologies or frameworks proposed in this work. It also, includes a prototype that facilitates the evaluation of the adoption of DevOps in the software development processes of the software development companies based on the indicators defined in the reference model.

\section{Conclusions and future work}

In the last ten years DevOps has become a topic of interest within the software industry. As it has been observed, although it is a relatively new concept and there is no common definition of what DevOps means, some SDC have carried out the implementation and adoption of certain practices related to DevOps. However, although there is coincidence in some of the terms used regarding the adoption of DevOps, for example, in the names of the proposed activities, there is still heterogeneity and therefore ambiguity in the terms. This is because each author covers DevOps from a particular perspective. So far, there is no evidence of a guide / standard to carry out the process of adoption and evaluation of DevOps. In this regard, the results obtained in the systematic mapping presented in this study demonstrate the novelty of this field and the need to develop a guide that simplifies the understanding of DevOps and allows its adoption, implementation and / or control in the SDC. Bearing in mind the shortcomings found in this current research stream, we have presented a detailed summary of our research proposal, which defines a set of elements with which to facilitate the activities related to DevOps. 


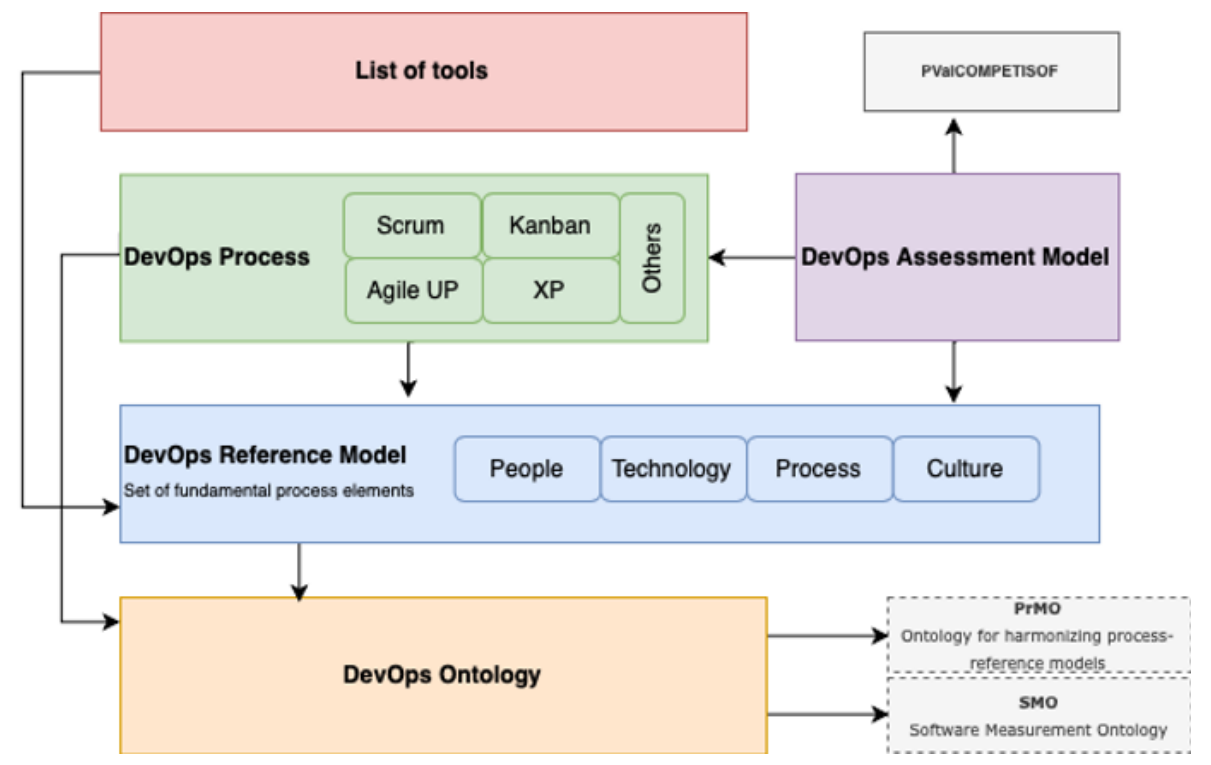

Figure 1: A summary of the proposed framework.

\section{Acknowledgments}

The professor Ph.D. César Pardo gratefully acknowledges the contribution of Universidad del Cauca, where he works as Associate Professor.

\section{References}

[1] P. Kruchten, The Rational Unified Process - An Introduction. Boston, MA, USA: Addison-Wesley-Longman, 2000.

[2] CMMI Institute, "Capability maturity model integration for development (cmmi-dev, v2.0)," 2018. [Online]. Available: https://bit.ly/2J2mGLB. [Accessed: 27-Mar-2020].

[3] ICONIX Software Engineering, "Iconix," 2019. [Online]. Available: https://bit.ly/3aAQLQ9 [Accessed: 27Mar-2020].

[4] G. Lory, D. Campbell and A. Robin, "Microsoft Solutions Framework v3 Overview," 2003.

[5] J. Schwaber and K. Sutherland, "The scrum guide the definitive guide to scrum: The rules of the game," 2017. [Online]. Available: https://bit.ly/2F7HKxd. [Accessed: 27-Mar-2020].

[6] M. Poppendieck and T.Poppendieck, Lean Software Development: An Agile Toolkit. Crawfordsville, IN, USA: Addison-Wesley Professional, 2003.

[7] K. Beck and C. Andres, Extreme Programming Explained: Embrace Change. Boston, MA, USA: AddisonWesley-Longman, 2004.

[8] A. Cockburn, "Crystal Clear: A Human-Powered Methodology for Small Teams.," Pearson Education, 2004.

[9] J. A. Highsmith, "Adaptive Software Development: A Collaborative Approach to Managing Complex Systems," vol. 12, 2000.

[10] C. Ladas, Scrumban-essays on kanban systems for lean software development. Seattle, WA, USA: Modus Cooperandi Press, 2009.

[11] H. Kniberg, Scrum and XP from the Trenches. Morrisville, NC, USA: Lulu.com, 2007.

[12] J. Sutherland, C. Jakobsen and K.Johnson, "Scrum and CMMI level 5: The magic potion for code warriors," in 41st Annual Hawaii International Conference on System Sciences (HICSS 2008), 2008, pp. 466-466.

[13] C. Pardo, P.Chilito, D. Viveros and F. Pino, "Scrum+: A scaled Scrum for the agile global software development project management with multiple models," Rev. Fac. Ing., 2019.

[14] A. Hochstein, R. Zarnekow and W.Brenner, "ITIL as common practice reference model for IT service management: formal assessment and implications for practice," 2005 IEEE Int. Conf. e-Technology, eCommerce e-Service, pp. 704-710., 2005.

[15] J. Young, G. Ridley and P. Carroll, "COBIT and Its Utilization: A Framework from the Literature," 47th Hawaii Int. Conf. Syst. Sci., p. 80233., 2014.

[16] ISO/IEC, "Calidad de los servicios TI," 2019. [Online]. Available: https://bit.ly/2HWudxi. [Accessed: 27Mar-2020]. 
[17] S. Samarawickrama and I. Perera, "Continuous scrum: A framework to enhance scrum with DevOps," in 2017 Seventeenth International Conference on Advances in ICT for Emerging Regions, 2017, pp. 1-7.

[18] C. Pardo and J. Masso, "Hacia una Ontología para el Gobierno de Desarrollo de Software en Pymes," Publicaciones e Investig., vol. 9, pp. 99-112, 2015.

[19] C. Pardo and J. Maso, "Revisión sistemática de la integración de modelos de desarrollo de software dirigido por modelos y metodologías ágiles," Inf. Técnico, vol. 8, pp. 87-99, 2016.

[20] M. Virmani, "Understanding Devops \& Bridging The Gap From Continuous Integration To Continuous Delivery," in Fifth International Conference on the Innovative Computing Technology (INTECH 2015). IEEE, 2015, pp. 78-82.

[21] I. Bucena and M.Kirikova, "Simplifying the DevOps Adoption Process," in BIR Workshops, 2017.

[22] S. Jones, J. Noppen, and F. Lettice, "Management challenges for DevOps adoption within UK SMEs," in Proceedings of the 2nd International Workshop on Quality-Aware DevOps - 2016, 2016, pp. 7-11.

[23] L. Riungu-Kalliosaari, S. Mäkinen, L. Lwakatare, J. Tiihonen and T. Männistö, "DevOps Adoption Benefits and Challenges in Practice: A Case Study," 590-597. 10.1007/978-3-319-49094-6_44, 2016.

[24] J. Michelsen, "Dysfunction Junction: A Pragmatic Guide to Getting Started with DevOps," pp. 1-26, 2014.

[25] K. Lees, J. Gardner and P. Eaton, "DevOps and Agile Development - A VMware Field Perspective," VMware, Inc., Palo Alto, CA, USA, 2020. [Online]. Available: https://bit.ly/3eVxcDc

[26] C. Prado, F. Pino and W. Ortega, "Mapeo sistemático sobre la evaluación de la agilidad en organizaciones de desarrollo de software," ITECKNE Innovación e Investig. en Ing., vol. 16, pp. 64-76, 2019.

[27] G. Ghantous and A. Gill, "DevOps: Concepts, Practices, Tools, Benefits and Challenges," in PACIS 2017, 2017.

[28] J. Guerrero, C. Certuche, K. Zúñiga and C. Pardo, "What is there about DevOps? Preliminary Findings from a Systematic Mapping Study," in JIISIC 2019, 2019.

[29] J. Paton-Romero and M. Piattini, "Green IT maturity models: A systematic mapping study," in 2017 12th Iberian Conference on Information Systems and Technologies (CISTI), 2017, pp. 1-6.

[30] K. Petersen, R. Feldt, S. Mujtaba and M. Mattsson, "Systematic mapping studies in software engineering," in EASE'08 Proceedings of the 12th international conference on Evaluation and Assessment in Software Engineering, 2008, pp. 68-77.

[31] B. Kitchenham, "Systematic review in software engineering," in Proceedings of the 2nd international workshop on Evidential assessment of software technologies - EAST '12, 2012, pp. 1-2.

[32] D. Budgen, M. Turner, P. Brereton and B. Kitchenham, "Using mapping studies in software engineering.," in PPIG 2008, 2008, pp. 195-204.

[33] M. Genero, L. Cruz, and M. Piattini, "Métodos de investigación en ingeniería del software, “. Bogotá, DC: Grupo Editorial ra-ma, 2014.

[34] M. Martins, "Devopsdays Organizing Guide," 2018. [Online]. Available: http://bit.ly/3bEPpVr. [Accessed: 27-Mar-2020].

[35] F. Erich, C. Amrit, and M. Daneva, "A qualitative study of DevOps usage in practice," J. Softw. Evol. Process, vol. 29, pp. 1-25, Jun. 2017.

[36] B. de França, H. Jeronimo and G. Travassos, "Characterizing DevOps by Hearing Multiple Voices, " New York, NY: Association for Computing Machinery, 2016.

[37] L. Chen, "Continuous Delivery: Overcoming adoption challenges," J. Syst. Softw., vol. 128, pp. 72-86, Jun. 2017.

[38] J. Wettinger, U. Breitenbücher and F. Leymann, "DevOpSlang - Bridging the Gap between Development and Operations," \& L. K. (eds) Villari, M., Zimmermann, W., Ed. Berlin, Heidelberg: Springer, 2014, pp. $108-122$.

[39] L. Lwakatare, P. Kuvaja and M. Oivo, "Dimensions of DevOps," in Agile Processes in Software Engineering and Extreme Programming, \& P. M. Lassenius C., Dingsøyr T., Ed. Helsinki, Finland: Springer, Cham, 2015, pp. 212-217.

[40] M. Kamuto, and J. Langerman, "Factors inhibiting the adoption of DevOps in large organisations: South African context," in 2nd IEEE International Conference on Recent Trends in Electronics, Information \& Communication Technology (RTEICT), 2017, pp. 48-51.

[41] V. Gupta, P. Kapur and D. Kumar, "Modeling and measuring attributes influencing DevOps implementation in an enterprise using structural equation modeling," Inf. Softw. Technol., vol. 92, pp. 75-91, Dec. 2017.

[42] F. Erich, C. Amrit and M. Daneva, "Report: DevOps Literature Review," 2014.

[43] R. Jabbari,N. Bin, K. Petersen and B. Tanveer, "What is DevOps?," in PXP '16 Workshops: Scientific Workshop Proceedings of XP2016, 2016, pp. 1-11.

[44] F. Elberzhager, T. Arif, M. Naab, I. Süß, I and S. Koban, "From Agile Development to DevOps: Going Towards Faster Releases at High Quality - Experiences from an Industrial Context," Vienna, Austria: Springer, Cham, 2017. 
[45] S. Krusche, L. Alperowitz, B. Bruegge, and M. Wagner, "Rugby: an agile process model based on continuous delivery," in RCoSE 2014 - Proceedings of the 1st International Workshop on Rapid Continuous Software Engineering, 2014, pp. 42-50.

[46] S. Klepper, S. Krusche, S. Peters, B. Bruegge and L. Alperowitz, "Introducing Continuous Delivery of Mobile Apps in a Corporate Environment: A Case Study," in 015 IEEE/ACM 2nd International Workshop on Rapid Continuous Software Engineering, 2015, pp. 5-11.

[47] G. Benguria, J. Alonso, I. Etxaniz,L. Orue-Echevarria and M. Escalante, "Agile Development and Operation of Complex Systems in Multi-technology and Multi-company Environments: Following a DevOps Approach," in European Conference on Software Process Improvement EuroSPI 2018, 2018, pp. 15-27.

[48] A. Nagarajan and S. Overbeek, "A DevOps Implementation Framework for Large Agile-Based Financial Organizations," in On the Move to Meaningful Internet Systems. OTM 2018 Conferences, M. R. (eds) Panetto H., Debruyne C., Proper H., Ardagna C., Roman D., Ed. Utrecht, Netherlands: Springer, Cham, 2018, pp. 172-188.

[49] M. Senapathi, J. Buchan, and H. Osman, "DevOps Capabilities, Practices, and Challenges," in Proceedings of the 22nd International Conference on Evaluation and Assessment in Software Engineering 2018 - EASE'18, 2018, pp. 57-67.

[50] L. Lwakatare, T. Kilamo, T. Karvonen, T. Sauvola, V. Heikkilä, J. Itkonen, and C. Lassenius, "DevOps in practice: A multiple case study of five companies," Inf. Softw. Technol., vol. 114, pp. 217-230, Oct. 2019.

[51] J. Cusick, "A Survey of Maturity Models from Nolon to DevOps and Their Applications in Process Improvement.," 2019.

[52] A. Hemon, B. Lyonnet, F. Rowe, and B. Fitzgerald, "From Agile to DevOps: Smart Skills and Collaborations," Inf. Syst. Front., pp. 1-19, Mar. 2019.

[53] C. Pardo, F. García, M. Piattini, F. Pino and M. Baldassarre, "A Reference Ontology for Harmonizing Process-reference Models," Rev. Fac. Ing. Univ. Antioquia, vol. 73, pp. 29-42, 2014.

[54] M. Barcellos, R. Falbo and R. Moro, "A Well-Founded Software Measurement Ontology," in FOIS 2010., vol. 209, pp. 213-226.

[55] D. Teixeira, R. Pereira, T. A. Henriques, M. Silva, and J. Faustino, "A Systematic Literature Review on DevOps Capabilities and Areas," International Journal of Human Capital and Information Technology Professionals, vol. 11, no. 2, pp. 1-22, 2020.

[56] L. Leite, C. Rocha, F. Kon, D. Milojicic, and P. Meirelles, "A Survey of DevOps Concepts and Challenges," ACM Comput. Surv. 52, 6, Article 127, 35 pages. 2019.

[57] M. Sánchez-Gordón and R. Colomo-Palacios, "Characterizing DevOps Culture: A Systematic Literature Review," in Proceedings of the Software Process Improvement and Capability Determination. SPICE 2018, pp. 3-15, 2018 .
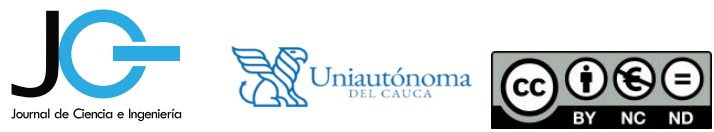